\title{
AUTOPSIA A LA CAJA SUCIA
}

\section{AUTOPSY TO DIRTY BOX}

Lorenzo Díaz: Sociólogo y escritor. lorenzo.diaz@aol.com

\section{CURRÍCULUM VITAE}

Sociólogo y escritor. Autor de los libros "La televisión en España" y "La década abominable". Actualmente está preparando un libro sobre la telebasura, que aparecerá en La Esfera de los Libros en este otoño.

\section{RESUMEN}

La presencia de espacios que basan su contenido en informar de la vida privada de famosos aumenta exponencialmente temporada tras temporada: el mercado televisivo español no deja de absorber nuevos productos de este tipo: en 1993 sólo existía el espacio rosa Corazón, corazón y 10 años después, el número de programas especializados asciende a más de 20 y casi todos ellos gozan de una excelente salud.

\section{PALABRAS CLAVE}

Televisión - Famosos - Audiencia

\section{ABSTRACT}


The presence of spaces based his report contained in the private lives of celebrities increases exponentially each season: the Spanish television market continues to absorb new products of this type: in 1993 there was only space pink heart, heart and 10 years later the number of specialized programs amounts to more than 20 and almost all of them enjoy excellent health.

\section{KEY WORDS}

Television - Celebrities - Audience

\section{TEXTO:}

La TELEVISION más vulgar y hedionda regresa con fuerza esta temporada. El hermano que no quisiéramos tener y la peor granja ibérica ya funcionan. El sociólogo reflexiona, quizás inútilmente.

Tengamos las ideas claras. La cuenta de resultados de las empresas televisivas: producto barato junto a una audiencia cotilla y de precario nivel cultural hacen posible que la mierda invada nuestra televisión. Y lo que es más alarmante, no hemos hecho nada más que empezar: estamos en la prehistoria Pronto llegarán las humillaciones en directo, zoofilias, autopsias, suicidios. Los canales piden más madera. ¿Es que no me creen?

La presencia de espacios que basan su contenido en informar de la vida privada de famosos aumenta exponencialmente temporada tras temporada: el mercado televisivo español no deja de absorber nuevos productos de este tipo: en 1993 sólo 
existía el espacio rosa Corazón, corazón y 10 años después, el número de programas especializados asciende a más de 20 y casi todos ellos gozan de una excelente salud. Si cogemos al azar un día de esta semana, el género rosa basuril coloca entre los 10 programas más vistos (martes, 7) con altísimos "shares" cuatro formatos: Aquí hay tomate $(26,8)$, Gran Hermano $(27,1)$, Gente $(28,1)$, La hora de la verdad $(30,4)$. Dos programas estrellas del género: Dónde estás corazón y Salsa rosa, tienen audiencias superiores a nuestros telediarios, con cuotas de pantalla superiores al 27\%. Y ahora llega La Granja con más de tres millones y un 27\% de "share". La televisión se ha vengado de los intelectuales que la han despreciado y se ha entregado en brazos de la llamada "ordinary people" española: una de las más incultas del mundo occidental desarrollado.

Lejos de la órbita de los profesionales, lo que le daría un tono artístico, la televisión cada día se parece más a la ruidosa clase media española: chillona, prepotente y proclive a entregarse a los bajos instintos. Por ello no sorprende que haya ido colocando en el escaparate de sus preferencias los programas que ella considera estrellas en su versión dura y "light". Dos ilustres damas del panorama mediático español envuelven en celofán sus magazines que también cantan y son culpables, en parte, del panorama que se observa desde el puente.

\section{$\underline{\text { SIN MITOS NI ESTRELLAS }}$}

Sorprende que una sociedad situada en tan buena posición en el "hit parade" de la riqueza, exhiba una fauna tan zarrapastrosa en su famoseo zarzuelero. Nuestros iconos mediáticos son peores que los del tardofranquismo cuando Los Codeso y Pajares perseguían suecas en Torremolinos. Son el lumpen de una sociedad que viste a la clase media del mundo a través de las tiendas de Zara. 
Hay que dejar de demonizar sólo a los productores. Hay que poner el ojo también en nuestra audiencia y ver lo homogénea que es televisivamente hablando. Salsa rosa o Tómbola lo mismo gusta a una venerable dama del barrio de Salamanca que a una maruja de Minglanilla (Cuenca). La gente dice que ve La 2 y los documentales de la National Geography y luego pierden el culo con Matamoros y la Marchante.

A nuestra burguesía siempre le ha gustado más Lina Morgan que Margarita Xirgu. Corín Tellado que Lope de Vega. El tinto de verano que el Vega Sicilia. Sólo un "target" muy reducido tiene acceso a la alta costura. Y así hemos llegado a un punto en el que un importante segmento de la población no tiene un producto televisivo que consumir. Es un público que no tiene mensaje televisivo y que no le queda más remedio que pasar por la caja de Polanco.

La sociedad española en su casi totalidad recibe alborozadamente el producto televisivo que se elabora. Ha percibido que la televisión ha sustituido la realidad, creando otra nueva. Ha creado mundos visuales donde trivializa objetos negativos: figuras del mal, violencia, horror, catástrofes. La nueva religión de la sociedad posmoderna es la televisión de la intimidad, la modalidad catódica de la confesión católica.

¿Está el personal harto de la telebasura? Los datos son concluyentes: más del 50\% de los españoles cree que la televisión es «vulgar y de mal gusto» (CIS, 2004). La califican de poco objetiva. Más objetiva ven la radio (casi un $60 \%$ de los encuestados le dan la máxima calificación). No obstante, el $90 \%$ de la población consume televisión, frente al 60\% de oyentes mayores de 18 años que tiene la radio.

Dice Forges que para que haya un Gran Hermano hacen falta millones de primos. Los comemierdas no son cuatro gatos, sino más de 15 millones de telespectadores diarios. Los programas basura como Crónicas marcianas están magistralmente 
hechos. La jauría de invitados se desloma por merecer los cinco minutos de fama, se degüellan, se insultan y se exhiben con una falta de pudor que casi enternece.

Los "killers" de la telebasura, Matamoros, la Marchante o Mariñas, los que juegan la Champions, son unos actores excelentes que interpretan magistralmente sus papeles. Raúl del Pozo ve en la telebasura una fiebre amarilla que ataca un público despolitizado, aburrido, desencantado, que sólo se emociona con chismes.

Cuando algún listillo reivindica más teleficción hay que recordarle que un empresario prefiere gastarse 30 millones de las antiguas pesetas en un Salsa rosa que 90 en Los Serrano. El paisaje después de la batallas es desolador para los llamados cejas altas que citan a Umberto Eco, a Juan Cueto, pero el resto de la sociedad se la refanfinfla y disfruta con Dinio, que recibe excursiones de cientos de marujas en sus bares de Puerto Banús. Edificante perla hedionda la que le escuché en Crónicas marcianas (6 de noviembre del 2001). Le pregunta Sardá: «¿Tú se la metías a Marujita Díaz?». Y el cubanito contestó: «Nunca, pero ella me la chupaba. Y yo pensaba en Sonia Moldes».

De canguro catódico a acompañante del abuelo: La televisión ha ido usurpando el papel de otros grupos en el llamado proceso de socialización del individuo. Es el canguro catódico, el pariente que nunca falla, el que acompaña al anciano en su soledad. Ocupa el terreno dejado por otras instituciones sociales (familia, escuela, Estado) y lo hace extendiendo y trivializando el campo del saber, sustituyendo un saber humanista por una especie de saber hacer, saber práctico; en suma, un saber mosaico muy representativo de la cultura de masas y de su imaginario de la evasión que puede paliar, sin embargo, ciertas carencias sociales, contribuir a reforzar el vínculo social y, en todo caso, servir de intermediario entre el ciudadano y el entorno social. Se consolida así una televisión mediadora. La televisión se impone como una gran casa de citas en la que todos cabemos y donde exhiben su levedad los seres 
menos relevantes, monstruos mediáticos de todo a cien, personajes kleenex, los que con el mínimo esfuerzo se han hecho con la caja y la popularidad.

Las televisiones crean sus propias factorías de monstruos, de frankenstein de corto recorrido que deambulan por las pasarelas televisivas para el regocijo del circo. La televisión no es la verdad. La televisión es un maldito parque de atracciones, un carnaval, una "troupe" de acróbatas, narradores de cuentos, bailarinas, cantantes, malabaristas. Es una fábrica para matar el aburrimiento. Si quieren saber la verdad, diríjanse a Dios, diríjanse a su gurú, a ustedes mismos, porque es la única manera de hallar la auténtica verdad. Ustedes no van a enterarse de la verdad por nosotros. Les diremos cuanto quieran oír.

¿Cómo poner freno a este desenfreno? ¿Creando un comité audiovisual como en otros países para controlar contenidos? Aunque el patio está para pocas ilusiones cuando uno ve, como dice Arturo Pérez Reverte, «a esas marujas en éxtasis, admirando aleladas a una vulgar pedorra, son un símbolo perfecto de lo que tenemos y de lo que merecemos tener. Por casposos, por imbéciles».

Se ha inaugurado una nueva etapa en los medios: la llamada globalización emocional que aparca el periodismo con ideas. El modelo audiovisual dominante ha dejado fuera del banquete mediático la reflexión. La causa de la mayoría de nuestros problemas sociales y políticos es la ignorancia creciente de la gente, causada en su mayor parte por la televisión Ver televisión en vez de leer, no permite a la gente detenerse o reflexionar, tener en cuenta los problemas y rechazar o combatirlos. Como las ocas o los avestruces que esconden la cabeza bajo tierra, los espectadores tragan y tragan televisión y jamás tienen tiempo para digerir lo que ven. 
